\title{
ANALISIS FAKTOR YANG MENDASARI HARAPAN KONSUMEN TERHADAP ATRIBUT PRODUK BERAS
}

\section{FACTORS THAT UNDERLIE CONSUMER EXPECTATIONS OF RICE PRODUCT ATTRIBUTES}

\author{
Kuswarini Kusno**1, Ronnie S. Natawidjaja ${ }^{1}$, Lies Sulistyowati ${ }^{1}$, \\ Bobby Rachmat Saefudin ${ }^{2}$ \\ ${ }^{1}$ Fakultas Pertanian Universitas Padjadjaran, J1. Raya Bandung Sumedang KM 21, Sumedang \\ ${ }^{2}$ Universitas Masoem \\ *E-mail: kuswarini.kusno@unpad.ac.id \\ (Diterima 08-06-2021; Disetujui 05-07-2021)
}

\begin{abstract}
ABSTRAK
Penelitian yang melibatkan pengukuran atribut beras yang kemudian dianalisis untuk mengetahui kepuasan konsumen sudah banyak dilakukan. Pada umumnya pengukuran tersebut dilakukan peneliti dengan menetapkan dimensi atau konstruknya lebih dahulu. Padahal beberapa atribut yang terdapat dalam suatu dimensi atau antar dimensi tersebut mungkin saja saling berkorelasi sehingga hasil penilaian konsumen dapat menjadi bias. Kota Bandung memiliki tingkat konsumsi beras tergolong tinggi. Tujuan penelitian adalah menganalisis faktor-faktor yang mendasari konsumen kota Bandung menilai tingkat kepentingan (harapan) atribut beras. Desain penelitian adalah kuantitatif dengan teknik penelitian survey terhadap 108 responden. Penarikan sampel menggunakan metode multi tahap (multistage sampling). Data primer dianalisis dengan metode Exploratory Factor Analysis (EFA). Hasil penelitian menunjukkan dari 14 variabel tingkat kepentingan atribut beras terbentuk 4 buah faktor yang mendasari penilaian konsumen terhadap atribut tersebut. Faktor 1 memuat 4 variabel tingkat kepentingan atribut yaitu banyaknya beras kepala, kebiasaan, lebih mengenyangkan, dan mudah diolah. Faktor 2 memuat 6 variabel tingkat kepentingan atribut beras yakni bentuk beras, derajat putih, banyaknya beras pecah, kandungan menir, panjang butir beras, dan kebulatlonjongan butir beras. Faktor 3 memuat variabel tingkat kepentingan atribut daya tahan beras, harga terjangkau, dan mudah didapat. Fakor 4 memuat tingkat kepentingan atribut prestise saja. Informasi dalam keempat belas variabel dapat diserap hampir 66\% oleh keempat buah faktor yang terbentuk.
\end{abstract}

Kata kunci: beras, atribut produk, tingkat kepentingan atribut beras, Exploratory Factor Analysis

\begin{abstract}
Many studies involving the measurement of rice attributes which are then analyzed to determine customer satisfaction have been carried out. In general, these measurements are carried out by researchers by determining the dimensions or constructs first. Whereas some of the attributes contained in a dimension or between these dimensions may be correlated with each other so that the results of consumer assessments can be biased. The city of Bandung has a relatively high level of rice consumption. The purpose of this study is to analyze the factors that underlie consumers in Bandung to assess the level of importance (expectations) of rice attributes. The research design is quantitative with survey research techniques to 108 respondents. Sampling using multistage sampling method. Primary data were analyzed by Exploratory Factor Analysis (EFA) method. The results showed that from the 14 variables of the importance of the rice attribute, 4 factors were formed that underlie consumer assessments of these attributes. Factor 1 contains 4 level of importance variables of rice attribute namely, the amount of beras kepala, habits, more filling, and easy to process. Factor 2 contains 6 level of importance variables of rice attributes, namely rice shape, whiteness, number of broken rice, groat content, rice grain length, and rice grain elongation. Factor 3 contains 3 level of importance variable namely, rice durability, affordable
\end{abstract}


prices, and easy to obtain. Factor 4 contains the level of importance of the prestige attribute only. Information in the fourteen variables can be absorbed almost $66 \%$ by the four factors formed.

Keywords: rice, product attributes, level of importance

\section{PENDAHULUAN}

Padi merupakan salah satu tanaman yang berpotensi untuk dikembangkan karena lebih dari 90\% masyarakat Indonesia mengkonsumsi beras (Pusdatin, 2015). Konsumsi beras Indonesia tahun 2017 hampir 150 $\mathrm{kg} /$ orang/tahun dimana tergolong tinggi di dunia; hanya Myanmar, Vietnam dan Bangladesh yang lebih tinggi dari Indonesia (Investment, 2017).

Banyaknya pilihan beras yang didasarkan atas jenis produk, kemasan, harga, rasa dan lain-lain serta pengaruh lingkungan budaya, kelas sosial, daya beli, motivasi, dan gaya hidup membentuk perilaku konsumen yang berbeda (K. Kusno et al., 2018) Akibatnya, produsen harus dapat memenuhi keinginan konsumen dalam segmen pasar yang dituju. Mengingat pentingnya beras bagi masyarakat, maka disamping meningkatkan produktivitas pemerintah juga harus mampu untuk memenuhi kebutuhan dan keinginan konsumen yang semakin berkembang seiring dengan berjalannya waktu. Aspek-aspek seperti kualitas, kuantitas, dan kontinuitas menjadi hal yang harus diperhatikan sehingga akan menciptakan kepuasan konsumen.

Konsumen mengambil keputusan pembelian berdasarkan persepsi terhadap atribut produk yang merupakan elemen sangat penting untuk menilai kepuasan (Tjiptono \& Diana, 2019). Kepuasan ditentukan antara lain oleh tingkat kepentingan/harapan konsumen terhadap atribut produk. Harapan konsumen terbentuk dari memperhatikan kinerja pada pembelian sebelumnya, nasihat teman dan kolega, serta informasi dari pemasar. Jika pemasar menetapkan harapan terlalu tinggi, maka pembeli akan kecewa apabila ternyata kinerja tidak memenuhi harapan. Sebaliknya, jika pemasar menetapkan harapan terlalu rendah, maka pembeli juga tidak akan tertarik walaupun sebenarnya kinerja produk memuaskan. Idealnya, pemasar berupaya meningkatkan harapan dengan menampilkan kinerja yang memenuhi harapan itu (Kotler \& Keller, 2012).

Penelitian yang melibatkan pengukuran atribut beras yang kemudian dianalisis untuk mengetahui kepuasan konsumen sudah banyak dilakukan. Pengukuran tersebut dilakukan peneliti 
dengan menetapkan dimensi atau konstruknya lebih dahulu. Padahal beberapa atribut yang terdapat dalam suatu dimensi atau antar dimensi tersebut mungkin saja saling berkorelasi sehingga hasil penilaian konsumen dapat menjadi bias. Oleh karena itu, penting diketahui lebih dahulu dimensi atau faktor yang mendasari (underlying factors) penilaian konsumen terhadap atribut beras. Dimensi tersebut akan berguna bagi konsumen sebagai dasar penilaian atau pendapatnya mengenai jenis produk yang dibeli (Supranto, 1997 dalam (Aji \& Widodo, 2010). Demikian pula bagi produsen dan pemasar serta penelitian mengenai konsumen beras.

Jawa Barat memiliki jumlah penduduk di perkotaan sebanyak 78,7\% pada tahun 2020; diprediksi menjadi $83,1 \%$ pada tahun 2025 dan $89,3 \%$ pada tahun 2035 (Badan Pusat Statistik, 2021). Peningkatan jumlah penduduk perkotaan mengakibatkan gaya hidup perkotaan (yang banyak menuntut produk dengan kualitas tinggi) akan sangat mempengaruhi pola permintaan beras. Kota Bandung memiliki tingkat konsumsi beras tergolong tinggi, yakni 595 ton per hari (Dinas Ketahanan Pangan dan Pertanian dalam (Rosadi, 2016).
Industri ritel mempunyai peranan yang strategis bagi perekonomian Indonesia. Penelitian (Natawidjaja et al., 2016) menyimpulkan bahwa terdapat 3 jenis ritel beras yang paling banyak dipilih oleh konsumen yaitu pasar tradisional (55\%), kios beras (25\%), dan supermarket (13\%).

Berdasarkan hal-hal yang dipaparkan di atas, dapat diidentifikasi pertanyaan penelitian: faktor-faktor apa yang mendasari konsumen kota Bandung menilai atribut produk beras. Tujuan penelitian adalah menganalisis faktorfaktor yang mendasari konsumen menilai tingkat kepentingan (harapan) atribut beras.

\section{METODE PENELITIAN}

Penelitian dilaksanakan di 3 jenis ritel: pasar tradisional, kios beras, dan supermarket di Kota Bandung pada tahun 2016 dengan desain penelitian kuantitatif dan teknik penelitian survey. Sampel dipilih menggunakan cara penarikan sampel berpeluang (probability sampling) yaitu penarikan sampel multi tahap (multistage sampling). Pada penelitian terdahulu kebanyakan penarikan sampelnya menggunakan cara penarikan sampel non peluang (seperti purposive sampling dan convenience sampling). 
Hanya 10 dari 30 kecamatan di Kota Bandung yang memiliki ketiga jenis ritel, yaitu: Kecamatan Andir, Antapani, Babakan Ciparay, Bandung Kulon, Buah Batu, Cidadap, Gedebage, Kiaracondong, Sukajadi, dan Kecamatan Unjungberung. Sesuai sumberdaya yang ada, dipilih sampel 3 kecamatan dengan teknik acak sederhana (simple random sampling). Kecamatan terpilih beserta banyaknya lokasi ritel di setiap kecamatan terpilih disajikan pada Tabel 1.

Tabel 1. Banyaknya Lokasi Ritel di Tiga Kecamatan Terpilih

\begin{tabular}{lccc}
\hline Kecamatan & \multicolumn{3}{c}{ Jenis Ritel } \\
Terpilih & PT & KB & SUP \\
\hline Bandung Kulon & 1 & 6 & 4 \\
Buah Batu & 1 & 3 & 4 \\
Cidadap & 1 & 3 & 4 \\
\hline
\end{tabular}

Keterangan: PT $=$ Pasar Tradisional; $\mathrm{KB}=$ Kios Beras; SUP = Supermarket.

Sumber: Data Primer, 2016

Berdasarkan Tabel 1, dari setiap kecamatan terpilih, diambil secara acak sederhana 1 lokasi pasar tradisional, 1 lokasi kios beras, dan 1 lokasi supermarket. Ukuran sampel responden $(n)=108$ disebar secara proporsional ke dalam lokasi ritel terpilih per kecamatan terpilih, sehingga ukuran sampel responden di setiap lokasi ritel terpilih $=$ 12. Pemilihan sampel responden dilakukan secara random. Randomisasi sampel dari populasi konsumen yang tak terhingga mengikuti kaidah: 1). setiap elemen terpilih berasal dari populasi yang sama, dan 2). setiap elemen dipilih secara independen (Anderson et al., 2011). Dalam penelitian ini sampel responden dipilih dari konsumen yang datang ke lokasi ritel khusus untuk membeli beras, bukan yang hanya untuk melihat-lihat. Dengan demikian, kaidah 1) terpenuhi. Responden yang dipilih adalah yang datang sendiri, bukan berkelompok. Jadi, kaidah 2) terpenuhi (Kuswarini Kusno et al., 2021). Kalau konsumen datang berkelompok, hanya seorang dari angota kelompok tersebut yang dipilih sebagai responden.

Variabel dalam penelitian ini adalah tingkat kepentingan 16 atribut beras yang diukur dengan skala Likert 5 nilai $(1=$ sangat tidak penting sampai dengan 5 = sangat penting). Ketujuhbelas variabel tersebut adalah tingkat kepentingan atribut bentuk beras (BB), derajat putih (DP), banyaknya beras kepala (BBK), banyaknya beras pecah (BBP), kandungan menir (KM), panjang butir beras (PBB), kebulatlonjongan butir beras (KB), kepulenan (KP), aroma nasi (AN), daya tahan beras (DTB), harga terjangkau (HT), mudah didapat (MD), kebiasaan (KS), prestise (P), lebih mengenyangkan (LM), dan mudah diolah (MDO). 
Data berupa data primer yang dikumpulkan melalui kuesioner dan wawancara dengan responden di lokasi ritel. Analisis data menggunakan analisis faktor eksploratori (Exploratory Factor Analysis/EFA) dengan bantuan program SPSS versi 25. Sebelum diolah, data item pertanyaan dalam kuesioner diuji dahulu reliabilitas dan validitasnya.

Uji reliabilitas menggunakan rumus Alpha Cronbach sebagai berikut:

$\alpha=\left(\frac{\mathrm{k}}{\mathrm{k}-1}\right)\left(1-\frac{\sum \sigma_{x_{i}}^{2}}{\sigma_{\mu}^{2}}\right)$

$\alpha=$ Reliabilitas kuesioner

$\sum \sigma_{x_{i}}^{2}=$ Total varians setiap item

$\mathrm{k} \quad=$ Banyaknya item pertanyaan

$\sigma_{\mu}^{2} \quad=$ Total varians semua item

Kuesioner reliabel jika $\alpha \geq 0,7$ (Taber, 2018).

Uji validitas menggunakan rumus korelasi Pearson sebagai berikut:

$r_{x y}=\frac{n \sum X Y\left(\sum X\right)\left(\sum Y\right)}{\sqrt{\left(n \sum X^{2}-\left(\sum X\right)^{2}\right)\left(n \sum Y^{2}-\left(\sum Y\right)^{2}\right)}}$

$\mathrm{r}_{\mathrm{xy}}=$ Koefisien korelasi

$\sum \mathrm{X}=$ Jumlah skor item pertanyaan

$\sum \mathrm{Y}=$ Jumlah skor total

$\mathrm{n}=$ Banyaknya responden

$\sum \mathrm{X}^{2}=$ Jumlah kuadrat skor item

$\sum \mathrm{Y}^{2}=$ Jumlah kuadrat skor total

$\sum X Y=$ Jumlah hasil kali skor item
Kuesioner valid jika $r_{x y} \geq$ nilai $r$ tabel untuk uji dwi arah (two-tailed) pada taraf nyata $5 \%$ dan derajat bebas $n-2$.

Selanjutnya data berskala Likert ditransformasi menjadi berskala interval dengan metode Successive Interval.

Analisis faktor merupakan teknik analisis multivariat untuk memecahkan masalah yang variabelnya tidak dibedakan atas variabel independen dan dependen. EFA mereduksi variabel asli yang saling berkorelasi menjadi variabel baru (yang disebut faktor atau dimensi) yang sudah tidak saling berkorelasi, dimana banyaknya faktor lebih kecil daripada banyaknya variabel asli (Kuswarini Kusno, 2019). Model matematiknya adalah: (Malhotra, 2010) $X_{i}=A_{i 1} F_{1}+A_{i 2} F_{2}+\cdots+A_{i m} F_{m}+V_{i} U_{i}$ dimana, $\mathrm{i}=1,2, \ldots, \mathrm{p} ; \mathrm{j}=1,2, \ldots, \mathrm{m}$ $\mathrm{X}_{\mathrm{i}}=$ variabel asli ke $\mathrm{i}$

$F_{j}=$ faktor kesamaan ke $\mathrm{j}$

$\mathrm{U}_{\mathrm{i}}=$ faktor unik ke $\mathrm{i}$ $A_{i j}=$ koefisien faktor kesamaan variabel asli ke i, faktor kesamaan ke j $\mathrm{U}_{\mathrm{i}}=$ koefisien faktor unik

\section{HASIL DAN PEMBAHASAN}

Sebaran lokasi ritel terpilih dan ukuran sampel responden disajikan pada Tabel 2. 
Tabel 2. Lokasi Ritel Terpilih dan Ukuran Sampel Responden

\begin{tabular}{lcccc}
\hline Kecamatan Terpilih & PT & KB & SUP & Total \\
\hline Bandung Kulon & Cijerah (12) & "Kios Beras" (12) & Borma Cijerah (12) & 36 \\
Buah Batu & Gordon (12) & Jl. Nilem (12) & Griya (12) & 36 \\
Cidadap & Gandok (12) & Zalfaa Beras, 12 & Griya Setiabudi, 12 & 36 \\
\hline Total & & &
\end{tabular}

Keterangan: PT = Pasar tradisional, $\mathrm{KB}=$ Kios Beras, SUP $=$ Supermarket, $(12)=$ ukuran sampel responden Sumber: Data Primer (2016)

Hasil Uji Reliabilitas dan Validitas Kuesioner

Dalam penelitian ini, satu variabel atau atribut memiliki satu pertanyaan.
Jadi banyaknya item = banyaknya variabel $=$ banyaknya atribut $=16$. Nilai Alpha Cronbach diperoleh $0,827>0,7$. Kesimpulannya adalah kuesioner reliabel.

Tabel 3. Hasil Uji Validitas

\begin{tabular}{cccccccccc}
\hline No. & Atribut & $r_{\text {hitung }}$ & $r_{0,025: 106}$ & Status & No. & Atribut & $r_{\text {hitung }}$ & $r_{0,025: 106}$ & Status \\
\hline 1 & BB &, 438 & & valid & 9 & AN &, 122 & & tidak valid \\
2 & DP &, 393 & & valid & 10 & DTB &, 537 & valid \\
3 & BBK &, 419 & & valid & 11 & HT &, 462 & & valid \\
4 & BBP &, 666 &, 189 & valid & 12 & MD &, 548 &, 189 & valid \\
5 & KM &, 343 & & valid & 13 & KS &, 583 & & valid \\
6 & PBB &, 533 & & valid & 14 & P &, 322 & & valid \\
7 & KB &, 457 & & valid & 15 & LM &, 508 & valid \\
8 & KP &, 186 & & tidak valid & 16 & MDO &, 668 & & valid \\
\hline
\end{tabular}

Dari Tabel 3 dapat dilihat bahwa nilai $\mathrm{r}$ hitung kepulenan $=0,186$ dan aroma nasi $=0,122$ dimana masingmasing $<\mathrm{r}$ tabel $=r_{0,025: 106}=0,189$ sehingga kedua item tidak valid. Karena itu keduanya dibuang sehingga hanya 14 variabel yang akan dianalisis selanjutnya.

\section{Faktor yang Mendasari Penilaian Konsumen terhadap Tingkat Kepentingan Atribut Beras}

Penelitian ini mengaplikasikan metode Analisis Faktor dari perspektif eksploratori. Dengan mereduksi 14 variabel tingkat kepentingan atribut beras (variabel asli) akan diperoleh variabel baru (disebut faktor atau dimensi atau variabel laten atau konstruk) yang mendasari konsumen melakukan penilaian tingkat kepentingan atribut beras tersebut. Karena itu hasil dan pembahasannya diuraikan berdasarkan langkah kerja EFA dalam SPSS sampai diperoleh faktor yang terbentuk.

Untuk menginterpretasi proses dan hasil analisis faktor dibutuhkan pemahaman konsep matriks dan vektor serta analisis multi variabel.

Langkah kerja EFA pada dasarnya terdiri atas: 1) menyusun matriks data yang berupa matriks korelasi antar variabel asli, 2) melakukan ekstraksi faktor atau disebut juga dekomposisi matriks data menjadi faktor-faktor, 3) 
merotasi faktor, dan 4) menginterprtasikan faktor hasil rotasi. Tujuan utama rotasi faktor adalah untuk mendapatkan struktur faktor yang lebih sederhana, sehingga peneliti lebih mudah menginterpretasi hasil analisisnya (Kuswarini Kusno, 2019).

\section{(1) Memeriksa Kecukupan Sampel}

Untuk mengukur kecukupan sampel agar diketahui apakah analisis faktor layak digunakan atau tidak maka dihitung nlai Kaiser-Meyer-Olkin measure of Sampling Adequacy (KMO). Jika nilai $\mathrm{KMO}>0,5$ maka analisis faktor dapat dilakukan tetapi jika nilai $\mathrm{KMO}<0,5$ maka analisis faktor tidak dapat dilakukan (Malhotra, 2010).

Hasil perhitungan KMO untuk 14 variabel asli menunjukkan nilai $\mathrm{KMO}=$ $0,763>0,5$ sehingga EFA dapat dilanjutkan. Nilai ini merupakan nilai KMO untuk seluruh variabel asli tingkat kepentingan atribut beras.

\section{(2) Menguji Korelasi diantara 14 Variabel Asli dengan Uji Bartlett}

Pengujian ini dilakukan untuk mengetahui apakah terjadi korelasi diantara variabel-variabel asli. Hasilnya adalah nilai $\mathrm{p}$ (peluang) $=0,00<$ taraf signifikansi $\alpha=0,05$ maka signifikan. Kesimpulannya, terdapat korelasi yang signifikan diantara 14 variabel tingkat kepentingan atribut beras. Jadi, proses analisis faktor dapat dilanjutkan.

\section{(3) Memeriksa Nilai KMO Setiap Variabel Asli}

Menurut (Field, 2009), nilai KMO untuk setiap variabel asli adalah nilai pada diagonal utama matriks anti image. Setiap nilai $\mathrm{KMO}$ harus $>0$,5. Jika nilai $\mathrm{KMO}<$ 0,5 maka variabel yang bersangkutan sebaiknya dipertimbangkan untuk dibuang dan proses EFA diulangi tanpa melibatkan variabel tersebut. Tabel 4 menunjukkan nilai KMO tiap variabel yaitu nilai yang terletak pada diagonal utama matriksnya lebih besar dari 0,5 sehingga EFA dapat dilanjutkan.

Tabel 4. Matriks Korelasi Anti-image dan Nilai KMO Variabel Tingkat Kepentingan Atribut Beras

\begin{tabular}{lccccccccccccccc}
\hline & BB & DP & BBK & BBP & KM & PBB & KB & DTB & HT & MD & KS & P & LM & MDO \\
\hline BB &, 835 &,- 161 &,- 037 &,- 097 &,- 251 &,- 032 &,- 040 &, 070 &,- 145 &, 064 &, 016 &,- 027 &, 178 &,- 207 \\
DP &,- 161 &, 866 &,- 152 &, 119 &,- 084 &,- 193 &,- 003 &, 014 &,- 036 &,- 012 &, 029 &,- 046 &, 072 &,- 107 \\
BBK &,- 037 &,- 152 &, 665 &,- 601 &, 379 &, 211 &,- 129 &,- 174 &,- 049 &, 212 &,- 385 &, 279 &, 035 &,- 308 \\
BBP &,- 097 &, 119 &,- 601 &, 747 &,- 402 &,- 270 &, 064 &, 052 &,- 030 &,- 253 &, 138 &,- 050 &,- 146 &, 149 \\
KM &,- 251 &,- 084 &, 379 &,- 402 &, 654 &,- 026 &,- 120 &,- 046 &, 012 &,- 107 &,- 153 &, 022 &, 032 &, 094 & -12 \\
PBB &,- 032 &,- 193 &, 211 &,- 270 &,- 026 &, 734 &,- 606 &,- 119 &, 088 &, 071 &,- 052 &,- 085 &, 005 &,- 072 \\
KB &,- 040 &,- 003 &,- 129 &, 064 &,- 120 &,- 606 &, 766 &, 107 &, 043 &,- 056 &, 013 &,- 010 &,- 016 &,- 041 \\
DTB &, 070 &, 014 &,- 174 &, 052 &,- 046 &,- 119 &, 107 &, 823 &,- 169 &,- 211 &,- 085 &,- 208 &, 222 &,- 153 \\
HT &,- 145 &,- 036 &,- 049 &,- 030 &, 012 &, 088 &, 043 &,- 169 &, 858 &,- 350 &,- 134 &,- 064 &,- 011 &, 057 \\
MD &, 064 &,- 012 &, 212 &,- 253 &,- 107 &, 071 &,- 056 &,- 211 &,- 350 &, 800 &, 124 &, 043 &,- 123 &,- 289 \\
KS &, 016 &, 029 &,- 385 &, 138 &,- 153 &,- 052 &, 013 &,- 085 &,- 134 &, 124 &, 829 &,- 168 &,- 341 &,- 028 \\
P &,- 027 &,- 046 &, 279 &,- 050 &, 022 &,- 085 &,- 010 &,- 208 &,- 064 &, 043 &,- 168 &, 738 &,- 133 &,- 051 \\
LM &, 178 &, 072 &, 035 &,- 146 &, 032 &, 005 &,- 016 &, 222 &,- 011 &,- 123 &,- 341 &,- 133 &, 802 &,- 446 \\
MDO &,- 207 &,- 107 &,- 308 &, 149 &, 094 &,- 072 &,- 041 &,- 153 &, 057 &,- 289 &,- 028 &,- 051 &,- 446 &, 833 \\
\hline \multicolumn{3}{l}{ Sumber: Pengolahan Data Primer $(2021)$} & & & & & & & & &
\end{tabular}




\section{(4) Ekstraksi Faktor untuk Menentukan Banyaknya Faktor yang Terbentuk}

Berbagai sumber menyatakan bahwa pendekatan yang paling sering digunakan untuk menentukan banyaknya faktor yang dipilih adalah pendekatan nilai eigen (eigen value).

Pada dasarnya 14 variabel asli menghasilkan 14 faktor (tertulis komponen pada Tabel 5) dan masingmasing faktor menghasilkan nilai eigennya. Contoh, faktor (komponen) 1 memiliki nilai eigen $=5,096$. Nilai eigen faktor $2=1,819$ dan seterusnya, nilai eigen faktor $16=0,138$. Tetapi pada prinsipnya tidak semua faktor diikutsertakan dalam proses analisis. Kaiser merekomendasikan variabel yang memiliki nilai eigen $>1$ layak dipertahankan sebagai pembentuk faktor. Tabel 5 menunjukkan bahwa nilai eigen 4 buah faktor pertama, berturut-turut = 5,096, 1,819, 1,215, dan 1,065 dimana setiap nilai tersebut $>1$. Jadi, dari 14 variabel tingkat kepentingan atribut beras terbentuk 4 faktor yang sudah tidak saling berkorelasi. Setiap faktor akan memiliki skor-skor faktornya.

Dari Tabel 5 kita juga dapat mengetahui bahwa faktor 1 dapat menjelaskan $36,400 \%$ dari total varians. Faktor 2 dapat menjelaskan 12,994\% dari total varians. Faktor 3 dan 4 masingmasing dapat menjelaskan 8,675\% dan $7,605 \%$ dari total varians. Maksudnya, 14 variabel direduksi menjadi 4 faktor tentunya mengakibatkan ada informasi yang hilang. Dengan kata lain, keempat buah faktor tidak dapat menyerap sepenuhnya semua informasi yang terdapat dalam 14 variabel tingkat kepentingan atribut beras. Proporsi informasi yang mampu diserap keempat buaf faktor $=36,400 \%+12,994 \%+$ $8,675 \%+7,605 \%=65,675 \%$.

Tabel 5. Faktor yang Terbentuk

\begin{tabular}{|c|c|c|c|c|c|c|}
\hline \multirow{3}{*}{ Komponen } & \multicolumn{5}{|c|}{ Total Varians yang dapat Dijelaskan } & \\
\hline & \multicolumn{3}{|c|}{ Nilai Eigen Awal } & \multicolumn{3}{|c|}{ Extraction Sums of Squared Loadings } \\
\hline & Total & $\%$ Varians & Kumulatif $(\%)$ & Total & $\%$ Varians & Kumulatif $(\%)$ \\
\hline 1 & 5,096 & 36,400 & 36,400 & 5,096 & 36,400 & 36,400 \\
\hline 2 & 1,819 & 12,994 & 49,395 & 1,819 & 12,994 & 49,395 \\
\hline 3 & 1,215 & 8,675 & 58,070 & 1,215 & 8,675 & 58,070 \\
\hline 4 & 1,065 & 7,605 & 65,675 & 1,065 & 7,605 & 65,675 \\
\hline 5 &, 888 & 6,346 & 72,021 & & & \\
\hline 6 &, 742 & 5,299 & 77,321 & & & \\
\hline 7 & ,674 & 4,815 & 82,136 & & & \\
\hline 8 &, 561 & 4,004 & 86,140 & & & \\
\hline 9 &, 528 & 3,768 & 89,908 & & & \\
\hline 10 & ,462 & 3,299 & 93,207 & & & \\
\hline 11 &, 300 & 2,146 & 95,353 & & & \\
\hline 12 & 281 & 2,010 & 97,363 & & & \\
\hline 13 & ,231 & 1,653 & 99,016 & & & \\
\hline 14 &, 138 &, 984 & 100,000 & & & \\
\hline
\end{tabular}


Selanjutnya EFA menghasilkan nilai komunalitas yang menggambarkan persentase varians suatu variabel asli yang dapat dijelaskan oleh semua faktor yang terbentuk.

Tabel 6. Komunalitas Setiap Variabel Tingkat Kepentingan Atribut Beras

\begin{tabular}{lcc}
\hline \multicolumn{3}{c}{ Komunalitas } \\
& Awal & Ekstraksi \\
\hline Bentuk Beras & 1,000 &, 552 \\
Derajat Putih & 1,000 &, 336 \\
Banyaknya Beras Kepala & 1,000 &, 835 \\
Banyaknya Beras Pecah & 1,000 &, 657 \\
Kandungan Menir & 1,000 &, 641 \\
Panjang Butir Beras & 1,000 &, 776 \\
Kebulatlonjongan & 1,000 &, 725 \\
Daya Tahan Beras & 1,000 &, 508 \\
Harga Terjangkau & 1,000 &, 666 \\
Mudah Didapat & 1,000 &, 638 \\
Kebiasaan & 1,000 &, 660 \\
Prestise & 1,000 &, 780 \\
Lebih Mengenyangkan & 1,000 &, 687 \\
Mudah Diolah & 1,000 &, 735 \\
\hline
\end{tabular}

Metode ekstraksi: Princial Component Analysis Sumber: Pengolahan Data Primer (2021)

Pada Tabel 6, komunalitas tingkat kepentingan bentuk beras $=0,552$ artinya keempat buah faktor dapat menjelaskan varians tingkat kepentingan bentuk beras $=55,2 \%$.

Varians tingkat kepentingan atribut derajat putih beras dapat dijelaskan oleh keempat faktor hanya sebesar $33,6 \%$. Angka ini tergolong kecil karena walaupun secara teori tidak ada ketentuan besarnya nilai komunalitas, tetapi dalam paraktek sebaiknya nilai komunalitas > 50\% (Hair et al., 2010). Dengan demikian, terserah pengambil keputusan, apakah atribut derajat putih akan dikeluarkan dari analisis lalu mengulangi proses EFA dari awal untuk 13 variabel, atau kah tetap seperti sekarang yaitu untuk 14 variabel dan analisis dilanjutkan.

Dalam penelitian ini, proses EFA tetap dilanjutkan (tanpa mengeluarkan atribut derajat putih beras).

\section{(5) Memasukkan Suatu Variabel Asli ke dalam Salah Satu Faktor yang} Terbentuk

Kita akan mengelompokkan variabel asli kedalam faktor. Pengelompokan ini didasarkan atas nilai factor loading (Tabel 7). Factor loading adalah nilai korelasi antara variabel asli dengan faktornya. Nilai factor loading dikatakan tinggi apabila $>$ 0,4 (Hair et al., 2010).

Pada Tabel 7 dapat dilihat factor loading panjang butir beras dengan Faktor 1 (component 1) dan Faktor 2 berturut-turut sebesar 0,584 dan 0,577 dimana kedua nilai ini termasuk tinggi karena lebih besar 0,4. Akibatnya, kita bingung apakah variabel tingkat kepentingan panjang butir beras masuk kedalam Faktor 1 atau Faktor 2. Untuk mengatasi hal ini, dilakukan rotasi faktor dengan metode Varimax. Menurut berbagai sumber, metode Varimax paling mudah diinterpretasi hasilnya karena struktur faktor yang terbentuk menjadi 
lebih sederhana. Struktur faktor yang

dimaksud adalah kombinasi liner antara variabel-variabel dengan

nilai factorloading-nya. memperlihatkan factor loading hasil rotasi.

Tabel 7. Factor Loading Setiap Variabel Tingkat Kepentingan Atribut Beras Sebelum Rotasi

\begin{tabular}{lcccc}
\hline Matiks Komponen $^{\text {a }}$ & \multicolumn{3}{c}{ Komponen } & \multicolumn{2}{c}{. } \\
& 1 & 2 &, 058 &,- 383 \\
\hline Bentuk Beras &, 515 &, 369 &,- 126 \\
Derajat Putih &, 469 &, 269 &,- 166 &,- 259 \\
Banyaknya Beras Kepala &, 681 &,- 410 &,- 369 &,- 256 \\
Banyaknya Beras Pecah &, 761 &, 083 &,- 071 &,- 141 \\
Kandungan Menir &, 393 &, 617 &, 293 &, 191 \\
Panjang Butir Beras &, 584 &, 577 &,- 220 &, 036 \\
Kebulatlonjongan &, 558 &, 523 &,- 322 &,- 202 \\
Daya Tahan Beras &, 568 &,- 202 &, 378 &,- 089 \\
Harga Terjangkau &, 571 &,- 235 &, 494 &, 154 \\
Mudah Didapat &, 656 &,- 061 &, 443 &, 714 \\
Kebiasaan &, 679 &,- 364 &,- 205 &, 267 \\
Prestise &, 365 &, 093 &, 357 &, 061 \\
Lebih Mengenyangkan &, 678 &,- 352 &,- 181 &,- 139 \\
Mudah Diolah &, 792 &,- 291 & &
\end{tabular}

Metode Ekstraksi: Principal Component Analysis

${ }^{\mathrm{a}} 4$ komponen terekstraksi

Sumber: Pengolahan Data Primer (2021)

Pada Tabel 8 tampak bahwa tingkat kepentingan panjang butir beras sudah dapat dimasukkan ke dalam sebuah faktor yakni Faktor 2, dengan nilai factor loading $=0,805$.

Keempat buah faktor yang terbentuk kemudian dapat diberi nama. Penamaan ini disesuaikan dengan kalimat pertanyaan dalam kuesioner mengenai tingkat kepentingan setiap atribut beras.

Dalam penelitian ini kalimat pertanyaan untuk semua atribut beras sama, hanya tergantung atributnya saja. Contoh, "Seberapa penting atribut kebulatlonjongan beras bagi anda?". Jika penamaan faktor sulit dibuat, tidak masalah, biarkan saja dinamai Faktor 1,
Faktor 2, Faktor 3, dan Faktor 4 Yang lebih penting, keempat buah faktor masing-masing sudah tidak berkorelasi dan memiliki data yang berupa skor faktor. Faktor yang terbentuk ini dapat dihubungkan dengan variabel lain untuk penelitian lanjutan.

Menurut Tjiptono \& Diana (2019), atribut produk dapat dikategorikan menjadi: (1) atribut biaya: harga pembelian, biaya pengoperasian, biaya reparasi, biaya ekstra, biaya instalasi, tunjangan tukar tambah, niali atau harga jual kembali; (2) atribut kinerja: durabilitas dan keawetan, kualitas bahan, konstruksi, keandalan, kinerja fungsional (akselerasi, nutrisi, rasa), efisiensi, 
keamanan; (3) atribut sosial: reputasi merek, citra status, popularitas di kalangan teman- teman, popularitas di kalangan keluarga, gaya atau corak, fashion dan (4) atribut kesediaan: tersedia di toko-toko setempat, syarat kredit, kualitas layanan yang tersedia di dealer setempat, waktu pengiriman.

Tabel 8. Factor Loading Setiap Variabel Tingkat Kepentingan Atribut Beras Setelah Rotasi Matiks Komponen $^{\mathrm{a}}$

\begin{tabular}{lcccc} 
& \multicolumn{2}{c}{ Komponen } & 3 & 4 \\
\hline Bentuk Beras & 1 & 2 &, 365 &,- 226 \\
Derajat Putih &, 049 &, 604 &, 103 &,- 071 \\
Banyaknya Beras Kepala &, 218 &, 522 &, 203 &,- 304 \\
Banyaknya Beras Pecah &, 823 &, 156 &, 396 &,- 144 \\
Kandungan Menir &, 451 &, 525 &, 373 &, 082 \\
Panjang Butir Beras &,- 255 &, 656 &,- 043 &, 299 \\
Kebulatlonjongan &, 191 &, 805 &,- 115 &, 221 \\
Daya Tahan Beras &, 249 &, 775 &, 608 &, 014 \\
Harga Terjangkau &, 304 &, 059 &, 780 &, 135 \\
Mudah Didapat &, 239 &, 033 &, 719 &, 138 \\
Kebiasaan &, 234 &, 218 &, 196 &, 838 \\
Prestise &, 768 &, 110 &, 230 &, 252 \\
Lebih Mengenyangkan &, 101 &, 116 &, 177 &, 095 \\
Mudah Diolah &, 763 &, 101 &, 322 & \\
\hline
\end{tabular}

Metode Ekstraksi: Principal Component Analysis.

Metode Rotasi: Varimax with Kaiser Normalization.

${ }^{a}$ Rotasi konvergen dalam 5 iterasi.

Sumber: Pengolahan Data Primer (2021)

Pada Tabel 8 dapat dilihat Faktor 1 memuat variabel tingkat kepentingan banyaknya beras kepala, kebiasaan, lebih mengenyangkan, dan tingkat kepentingan mudah diolah. Keempat buah atribut ini menurut kategorisasi yang dirumuskan oleh Tjiptono \& Diana (2019) di atas, dapat diidentifikasi masuk kedalam 2 buah kategori. Pertama, banyaknya beras kepala, lebih mengenyangkan, dan mudah diolah masuk kedalam kategori atribut kinerja; kedua, kebiasaan masuk kedalam kategori atribut sosial. Jadi, kita sulit menamai Faktor 1 dengan satu kalimat pendek jika mengacu pada kategorisasi tersebut. Karena itu Faktor 1 lebih baik tidak diberi nama.

Faktor 2 memuat tingkat kepentingan bentuk beras, derajat putih, banyaknya beras pecah, kandungan menir, panjang butir beras, dan tingkat kepentingan atribut kebulatlonjongan butir beras. Semua variabel pembentuk Faktor 2 ini dapat diidentifikasi termasuk kategori atribut kinerja. Jika dicermati lebih rinci, kelima variabel pembentuk faktor 2 ini berkenaan dengan keadaan fisik beras yang dilihat sekilas, maka Faktor 2 dapat dinamai Kinerja Fisik Beras yang Dilihat Sekilas. 
Faktor 3 mengandung variabel tingkat kepentingan atribut daya tahan beras, harga terjangkau, dan tingkat kepentingan mudah didapat. Daya tahan beras dapat masuk ke kategori kinerja. Harga terjangkau masuk ke kategori atribut biaya. Kemudian mudah didapat dapat dimasukkan ke kategori atribut kesediaan. Dengan demikian Faktor 3 tidak mudah untuk diberi nama. Dalam penelitian (Natawidjaja et al., 2016) dan (K. Kusno \& Samsudin, 2017), atribut daya tahan beras, bersama dengan atribut kepulenan nasi dan aroma nasi dikelompokkan dalam faktor/dimensi mutu beras. Dalam penelitian ini kepulenan dan aroma nasi justru tidak dianalisis karena terbukti tidak valid.

Faktor 4 memuat tingkat kepentingan atribut prestise saja, sehingga Faktor 4 cukup dinamai Prestise saja.

\section{KESIMPULAN DAN SARAN}

\section{Kesimpulan}

Terbentuk 4 buah faktor yang mendasari penilaian konsumen beras di kota Bandung terhadap 14 variabel tingkat kepentingan atribut beras. Keempat buah faktor dapat menyerap informasi yang terkandung dalam keempat belas variabel tersebut sebesar $65,675 \%$.

Faktor 1 memuat 4 variabel tingkat kepentingan atribut beras yaitu: banyaknya beras kepala, kebiasaan, lebih mengenyangkan, dan tingkat kepentingan mudah diolah.

Faktor 2 memuat 6 variabel tingkat kepentingan atribut beras yakni bentuk beras, derajat putih, banyaknya beras pecah, kandungan menir, panjang butir beras, dan kebulatlonjongan butir beras.

Faktor 3 mengandung variabel tingkat kepentingan atribut daya tahan beras, harga terjangkau, dan mudah didapat. Fakor 4 memuat tingkat kepentingan atribut prestise saja.

\section{Saran}

Untuk melakukan analisis data dengan metode Exploratory Factor Analysis, data penelitiannya harus dari sampel berpeluang. Hal ini disebabkan dalam proses EFA terdapat tahapan pengujian hipotesis, yaitu pengujian koefisien korelasi populasi.

\section{UCAPAN TERIMA KASIH (Jika ada)}

Penulis menyampaikan terima kasih kepada pihak Perhimpunan Ekonomi Pertanian (PERHEPI) Pusat 
atas bantuan pendanaan untuk pengumpulan data penelitian ini.

\section{DAFTAR PUSTAKA}

Aji, J. M. M., \& Widodo, A. (2010). Perilaku Konsumen pada Pembelian Beras Bermerk dI Kabupaten Jember dan Faktor yang Mempengaruhinya. $J$ SEP, 4(3), 12-24.

Anderson, D. R., Sweeney, D. J., \& Williams, T. A. (2011). Statistics for Business and Economics lle (J. W. Calhoun (ed.); 11 ed.). South-Western Cengage Learning.

Badan Pusat Statistik. (2021). Persentase Penduduk Daerah Perkotaan menurut Provinsi 2010-2035. https://www.bps.go.id/statictable/2014/ 02/18/1276/persentase-pendudukdaerah-perkotaan-menurut-provinsi2010-2035.html

Field, A. (2009). Discovering Statistics Using SPSS. SAGE Publications.

Hair, J. F., Black, W. C., Babin, B. J., \& Anderson, R. E. (2010). Multivariate Data Analysis (Seventh ed). Prentice Hall. https://www.academia.edu/41117363/ Multivariate_Data_Analysis_7th_Editi on_by_Joseph_F_Hair_Jr

Investment, I. (2017). Beras. https://www.indonesia-

investments.com/id/bisnis/komoditas/b eras/item 183

Kotler, P., \& Keller, K. lane. (2012). Manajemen Pemasaran Jilid 1 dan 2 Terjemahan (13 ed.). Erlangga.

Kusno, K., Imannurdin, A., Syamsiyah, N., \& Djuwendah, E. (2018). Analysis of rice purchase decision on rice consumer in Bandung city. IOP Conference Series: Earth and Environmental Science, 142(1). https://doi.org/10.1088/17551315/142/1/012039

Kusno, K., \& Samsudin, I. A. (2017). Analisis Kepuasan Konsumen Beras di Pasar Tradisional, Kios Beras, dan Supermarket Kecamatan bandung kulon, Kota Bandung. In H. Hapsari, I.
Setiawan, E. Wulandari, S. N. Wiyono, N. Syamsiyah, G. W. Mukti, R. A. Budi Kusumo, P. Pardian, \& I. Rahadian (Ed.), Daya Saing Berkelanjutan Agribisnis Spesifik Lokal (hal. 537-543). Departemen Sosial Ekonomi Pertanian Fakultas Pertanian Universitas Padjadjaran.

Kusno, Kuswarini. (2019). Intisari teknik analisis faktor (M. H. Karmana \& E. Wulandari (ed.); 1 ed.). Unpad Press.

Kusno, Kuswarini, Liandy, R. S., Mukti, G. W., \& Sadeli, A. H. (2021). Driven Factors for Purchasing Decision and Satisfaction of Organic Rice Consumers on Supermarket - A Study in Indonesia. Journal of Agricultural Sciences - Sri Lanka, 16(2), 271-282. https://doi.org/http://doi.org/10.4038/ja s.v16i2.9333

Malhotra, N. K. (2010). Marketing Research: An Applied Orientation, (6 ed.). Pearson Education Inc. Upper Saddle River.

Natawidjaja, R. S., Sulistyowati, L., Kusno, K., Aryani, D., \& Rachmat, B. (2016). Analisis Preferensi, Kepuasan, dan Willingness to Pay Konsumen Beras di Kota Bandung. https://doi.org/10.22487/j24775398.20 16.v2.i2.6719

Rosadi, D. (2016). Konsumsi beras di Kota Bandung capai 595 ton per hari. https://bandung.merdeka.com/halobandung/konsumsi-beras-di-kotabandung-capai-595-ton-per-hari161208y.html

Taber, K. S. (2018). The Use of Cronbach' s Alpha When Developing and Reporting Research Instruments in Science Education. Res Sci Educ, 1273-1296. https://doi.org/10.1007/s11165-0169602-2

Tjiptono, F., \& Diana, A. (2019). Kepuasan Pelanggan. Konsep, Pengukuran, \& Strategi (A. Diana (ed.); 1 ed.). ANDI. 